\title{
SCIDOC
}

\author{
International Journal of Dentistry and Oral Science (IJDOS) \\ ISSN: 2377-8075
}

\section{Hydroxyproline Levels in Gingiva and GCF in Patients with and without Chronic Periodontitis}

Research Article

Vishali Ravi ${ }^{1}$, Deepa Ponnaiyan ${ }^{2}$, P.S.G.Prakash ${ }^{2}$, Harinath.P2, Arya Mitra Loka ${ }^{3}$, Anie Mary Paul ${ }^{4}$

${ }^{1}$ Reader, Department of Periodontics, Panineeya institute of Dental sciences Hyderabad, India.

${ }^{2}$ Professor, Department of Periodontics, SRM Dental College, Ramapuram, Chennai, India.

${ }^{3}$ Postgraduate student, Department of Periodontics, SRM Dental College, Ramapuram, Chennai, India.

${ }^{4}$ Specialist Surgeon, Private Practice, Review Board Member Acta International Scientific Dental Journal.

\section{Abstract}

Aim: The aim of this study was to compare hydroxyproline levels in both in the gingival tissue samples and gingival crevicular fluid from periodontally healthy subjects and chronic periodontitis subjects.

Patients and Methods: A total of 40 individuals, 20 from each group, were studied. After recording clinical parameters, GCF was obtained without any contamination. The gingival samples were harvested by full thickness flap operation from periodontitis patients and immediately after the extraction of the teeth for orthodontic reasons from controls. ELISA analysis was performed to determine the hydroxyproline levels.

Statistical Analysis: Mean values were compared by one way ANOVA and Mann-Whitney U test student t-test was used to compare continuous variables between two groups and Spearman correlation test was used to correlate hydroxyproline with clinical parameters for both the groups. A statistically significant p-value of 0.05 was used.

Results: Clinical parameters in both the groups were positively correlated with hydroxyproline levels and higher concentrations of hydroxyproline were found in both GCF $(844.5 \pm 458.1$ and $149.7 \pm 62.2)$ and gingival tissue samples $(1412.2 \pm 627.7$ and $217.4 \pm 115.7$ ) of group II subjects as compared with the group I subjects

Conclusion: Hydroxyproline can serve as a biomarker in periodontal disease.

Keywords: Hydroxyproline; Collagen; Periodontitis; Biomarker.

\section{Introduction}

The periodontium's tissues are in a delicate balance between health and disease, as well as repair and regeneration. Tissue destruction will exceed repair during active periodontal disease, resulting in alterations in the quality and amount of connective tissue elements [1-6].

Collagen being the most abundant protein is considered as the most important in terms of tooth support. The bulk of the gingiva is composed of connective tissue [7] which contains high levels of collagen [2]. It accounts for about $60 \%$ of the total proteins in normal healthy gingiva [8] and is also major constituent of periodontal ligament and alveolar bone. It is composed of different amino acids, the most important of which are glycine, proline, hydroxylysine and hydroxyproline. Periodontal disease progresses with the loss of collagen fibres attached to the cemental surface, apical migration of the junctional epithelium, formation of periodontal pockets, and as well as resorption of alveolar bone [9-13]. $70 \%$ of the collagen immediately close to the junctional epithelium is lost at an early stage of inflammation.

Collagen is more abundant than: these other hydroxyproline containing proteins and comprises one third of total body protein Undenfriend S et al 1966 [14], Whitehead RG et al [15] 1965, $60 \%$ of the total proteins in normal healthy gingiva and also as a major constituent of periodontal ligament and alveolar bone.

Hydroxyproline is an essential amino acid that is created after protein synthesis by the enzyme prolyl hydroxylase hydroxylation of the amino acid proline as a post translational alteration. Collagen stability is promoted by hydroxyproline and proline. They enable

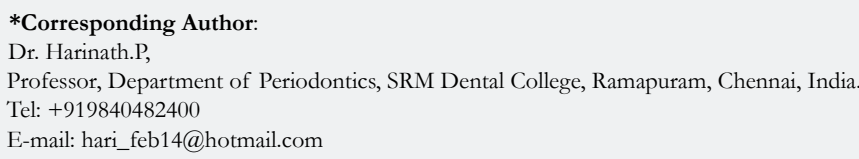

Copyright: Dr. Harinath.P ${ }^{\circ}$ 2021. This is an open-access article distributed under the terms of the Creative Commons Attribution License, which permits unrestricted use, distribution and reproduction in any medium, provided the original author and source are credited. 
the collagen helix to be twisted sharply. By establishing hydrogen bonds, it aids in the integrity of collagen's triple-helical structure. Gingival crevicular fluid (GCF) carries the most of tissue breakdown products into the gingival crevice [16]. Several connective tissue components' levels in GCF could be markers of gingival tissue breakdown. The levels of hydroxyproline have been investigated in both the gingiva and the GCF [17-21].

Thus, the aim of the present study was to detect and quantify the levels of hydroxyproline in GCF and gingival tissue samples in periodontally diseased and healthy subjects, and additionally to correlate clinical parameters with hydroxyproline concentration.

\section{Materials and Methods}

A total of 40 individuals were recruited by convenience sampling from the outpatient clinic of SRM Dental College and Hospital, Ramapuram, Chennai. They were categorized into two groups. Group I comprising of 20 periodontally healthy subjects, Group II comprising of 20 chronic periodontitis subjects. Ethical clearance was given by the Institutional Review Board of SRM University, Ramapuram, Chennai (SRMU/M\&HS/SRMDC/2010/ M.D.S-PG Student/104). Before GCF and gingival tissue sample collection, Informed consent was obtained from all the subjects.

\section{Inclusion and Exclusion Criteria}

Inclusion criteria include 40 systematically healthy subjects of both genders with an age range of 15 to 45 years and patients with no drug history of immunosuppressants, anti-inflammatory, antibiotics also patients who didn't undergo any periodontal treatment during the past 3 months were included during this study. The study excluded pregnant and breastfeeding women, smokers, patients with chronic inflammatory conditions, and individuals with acute infections.

Clinical Examination: Age, gender, smoking habits, and clinical periodontal examination were assessed by one skilled examiner. Clinical parameters like pocket probing depth (PD) and clinical attachment loss (CAL) were calculated on all 6 sites per tooth (mesiobuccal, mid buccal, distobuccal, distolingual, mid lingual, and mesiolingual) with a UNC-15 probe and also Plaque index [22], OHIS [23] (green and vermillion 1964) and Russel's periodontal index [24] were recorded.

GCF Sample Collection: Subjects were made to sit comfortably in an upright position on the dental chair with adequate illumina- tion after recording indices and examining periodontal condition. For sampling, the site with the greatest probing depth was chosen and dried using isolated using cotton rolls. By putting 1-5 microlitre calibrated volumetric micro-capillary pipettes at the gingival border, crevicular fluid was obtained by Cimasoni et al method [25]. GCF samples that were contaminated were discarded. The samples were centrifuged, and the supernatant was kept at $-70^{\circ} \mathrm{C}$. The samples were then assayed for hydroxyproline concentration by using the Quantikine human hydroxyproline ELISA kit (USCN life, China). and ELISA analysis was performed as per manufacturers instruction and absorbance values were determined by an ELISA Reader in picogram/millilitre values.

\section{Gingival tissue sample}

The gingival samples were obtained from chronic periodontitis patients using a full thickness flap operation, and from the control group immediately after tooth extraction for orthodontic reasons. The samples were then assayed for hydroxyproline concentration by using the Quantikine human hydroxyproline ELISA kit as per manufacturers instruction.

\section{Statistical analysis}

The Kruskal-Wallis one-way ANOVA was used to compare mean values between study groups, followed by the Mann-Whitney U test. Bonferroni correction procedure was employed to adjust the p-values for multiple comparisons. Spear man Rank Correlation analysis was done to assess the relationship between various study parameters. In the present study, $\mathrm{p}<0.05$ was considered as the level of significance.

\section{Results}

A total of 40 subjects including both males and females were recruited in the study. In group I there was male predominance with 15 males and 5 females subjects with a mean of $19.4 \pm 3$ years and group II consists of 15 males and 5 females with mean of $38.5 \pm 4.1$ years. In GCF, group I had a mean hydroxyproline level of 149.7 62.2, while group II had a mean hydroxyproline level of 844.5458 .1 . The mean hydroxyproline levels in gingival tissue samples from groups I and II were 217.4115 .7 and 1412.2 627.7 , respectively.

Comparison of clinical parameters and hydroxyproline between groups are shown in table 1 . All periodontal clinical parameters were highly significant and positively correlated with hydroxypro-

Table 1. Comparison of clinical parameters and hydroxyproline between groups.

\begin{tabular}{|c|c|c|c|}
\hline Variables & Group I (mean \pm S.D) & Group II (mean \pm S.D) & p-value \\
\hline OHI & $1.35 \pm 0.49$ & $5 \pm 1.03$ & $<0.001$ \\
\hline PI & $0.78 \pm 0.26$ & $1.98 \pm 0.04$ & $<0.001$ \\
\hline RI & $0.75 \pm 0.44$ & $7.20 \pm 1$ & $<0.001$ \\
\hline PPD & $2.20 \pm 0.52$ & $7 \pm 0.92$ & $<0.001$ \\
\hline CAL & 0 & $6.05 \pm 0.94$ & $<0.001$ \\
\hline GCF $(\mathrm{P} \mathrm{mol} / \mathrm{ml})$ & $149.7 \pm 62.2$ & $844.5 \pm 458.1$ & $<0.001$ \\
\hline Tissue samples $(\mathrm{P} \mathrm{mol} / \mathrm{ml})$ & $217 \pm 115.7$ & $1412 \pm 627.7$ & $<0.001$ \\
\hline
\end{tabular}

OHI- Oral Hygiene Index, PI- Plaque Index, RI- Russel periodontal Index, PPD- Pocket Probing Depth, CAL- Clinical Attachment Loss, GCF- Gingival Crevicular Fluid. 
Table 2. Spearman's correlation analysis of GCF hydroxyproline with clinical parameters in each study groups.

\begin{tabular}{|c|c|c|c|}
\hline Group & Clinical parameters & Correlation coefficient & p-value \\
\hline Group I & OHI & 0.25 & 0.05 \\
\hline & PI & 0.24 & 0.05 \\
\hline & RI & 0.22 & 0.05 \\
\hline & PPD & 0.18 & 0.05 \\
\hline & CAL & 0 & - \\
\hline Group II & OHI & 0.25 & 0.05 \\
\hline & PI & 0.21 & 0.05 \\
\hline & RI & 0.11 & 0.05 \\
\hline & PPD & 0.12 & 0.05 \\
\hline & CAL & 0.1 & 0.05 \\
\hline
\end{tabular}

OHI- Oral Hygiene Index, PI- Plaque Index, RI- Russel periodontal Index, PPD- Pocket Probing Depth, CAL- Clinical Attachment Loss.

Table 3. Spearman's correlation analysis of gingival tissue hydroxyproline with clinical parameters in each study group.

\begin{tabular}{|c|c|c|c|}
\hline Group & Clinical parameters & Correlation coefficient & p-value \\
\hline Group I & OHI & 0.2 & 0.04 \\
\hline & PI & 0.21 & 0.04 \\
\hline & RI & 0.24 & 0.05 \\
\hline & PPD & 0.16 & 0.03 \\
\hline & CAL & 0 & \\
\hline Group II & OHI & 0.18 & 0.03 \\
\hline & PI & 0.17 & 0.04 \\
\hline & RI & 0.09 & 0.001 \\
\hline & PPD & 0.06 & 0.001 \\
\hline & CAL & 0.04 & 0.001 \\
\hline
\end{tabular}

OHI- Oral Hygiene Index, PI- Plaque Index, RI- Russel periodontal Index, PPD- Pocket Probing Depth, CAL- Clinical Attachment Loss.

line levels in both the groups of gingival tissues and GCF. In both the groups of GCF and gingival tissue samples, Spearman's rank correlation was used to assess the correlations between hydroxyproline levels and clinical parameters (OHI, PI, RI, PPD, CAL) are shown in table 2 and table 3.

\section{Discussion}

Inflammation and destruction of the periodontal tissues are early and ongoing events in the periodontal disease process. Due to the low compliance of the gingival tissues and the high hydraulic conductance of the crevicular epithelium, the major portion of the breakdown products are washed of the tissues with the inflammatory exudates to appear in the gingival crevicular fluid Pashley et al 1976 [26].

Active phase of periodontal disease process can be measured or assessed by the qualitative analysis. of the constituents of gingival fluid M.V Subramanian [27] which include some of the biomarkers like specific cytokines, metalloproteinases, host derived enzymes, proteins and hydroxyproline Myriam A.Koss [28]. Amino acids like hydroxyproline is derived majorly from collagen and also as small quantities from elastin and complement component Ciq Johnston CS et al 1985 [29]. The presence of protein, and its breakdown products including hydroxyproline and other periodontal diseases acids explored by Svansberg and Akalin et al 92 [16].

The study was carried out on 40 systematically healthy patients and the results of the present study suggest that increased hydroxyproline levels in GCF could be due to inflammatory periodontal condition. In the present study the mean hydroxyproline concentration in gingival crevicular fluid was 149.7+62.2 in group 1 , and $844.5+458$. in group II. A significant difference $(p<0.001)$ was found in the Hydroxyproline concentration between group I and II which correlates with the study done by Akalin et al 1993 [30] who found that Hydroxyproline levels were higher in gingival tissue and GCF of patients with juvenile Periodontitis, Periodontitis, and adult periodontitis patients compared to rapidly progressive periodontally healthy controls. Myriam et al 2010 [28] conducted a study which showed Hydroxyproline values raised with the severity of the disease and these results are directly associated to the collagenolytic activity. The current study results are also similar to the study conducted in saliva samples by Myriam et al 2009 [31] which stated the hydroxyproline values differs signifi- 
cantly between the periodontitis and healthy group.

The mean hydroxyproline concentration in gingival tissue samples was 217.4 115.7 in group 1, and 1412.24627.7 in group II. A significant difference ( $\mathrm{p}-0.001)$ was found in the Hydroxyproline concentration between group I and II. The indices recorded and their ultimate result correlates with the presence of hydroxyproline in crevicular fluid and tissue samples which has been revealed through the present study. The findings of the present study demonstrated higher gingival Hydroxyproline levels compared to GCF Hydroxyproline levels in healthy and periodontitis groups. This is consistent with the study done by Ferda Alev Alkalin 1993 [30], who demonstrated higher gingival Hydroxyproline levels in periodontitis samples than in Controls.

The results of the present study also correlates that hydroxyproline being a major constituent of collagen, its qualitative assessment in GCF samples of periodontitis patients has proved its role as a bio-marker in the progression of periodontal disease. Further studies with larger sample size and comparing various severities of periodontitis like mild, moderate and severe forms and also considering shallow and deep pockets are required to quantify the amount of hydroxyproline content with the severity of periodontal disease.

\section{References}

[1]. Narayanan AS. Connective tissues of the periodontium: a summary of current work. Coll Rei Res. 1983 Jan 1;3(1):33-64.

[2]. Narayanan AS, Page RC, Meyers DF. Characterization of collagens of diseased human gingiva. Biochem. 1980 Oct 1;19(22):5037-43.

[3]. Narayanan AS, Page RC, Kuzan F. Collagens synthesized in vitro by diploid fibroblasts obtained from chronically inflamed human connective tissue. Lab Invest. 1978 Jul;39(1):61-5.Pubmed PMID: 682592.

[4]. Page RC. Biochemical aspects of the connective tissue alterations in inflammatory gingival and periodontal disease. Int. dent. J. 1973;23:455-69.

[5]. Page RC, Schroeder HE. Pathogenesis of inflammatory periodontal disease. A summary of current work. Lab Invest. 1976 Mar;34(3):235-49.Pubmed PMID: 765622.

[6]. Page RC, Narayanan AS, Schroeder HE. Connective tissue composition and collagen synthesis in diseased and normal gingiva of adult dogs with spontaneous periodontitis. Arch Oral Biol. 1980;25(11-12):727-36.Pubmed PMID: 6943992.

[7]. Grant DA, Stern IB, Listgarten MA. Periodontics in the Tradition of Gottlieb and Orban, 6th ed. St. Louis: The C.V. Mosby Co.; 1988:41- 44

[8]. Page RC, Simpson DM, Ammons WF, Schectman LR. Host tissue response in chronic periodontal disease: III. Clinical, histopathologic and ultrastructural features of advanced disease in a colony-maintained marmoset. J. Periodontal Res. 1972 Aug;7(4):283-96.

[9]. Carneiro J, Leblond CP. SUITABILITY OF COLLAGENASE TREATMENT FOR THE RADIOAUTOGRAPHIC IDENTIFICATION OF NEWLY SYNTHESIZED COLLAGEN LABELED WITH H-GLYCINE OR H-PROLINE. J Histochem Cytochem. 1966 Apr;14(4):334-44.
[10]. Sodek J. Collagen turnover in periodontal ligament. In: Norton LA, Burstone CJ, eds. The Biology of Tooth Movement. Boca Raton, FL: CRC Press, Inc.; 1989:167-181.

[11]. Page RC, Ammons WF. Collagen turnover in the gingiva and other mature connective tissues of the marmoset Saguinus oedipus. Arch Oral Biol. 1974 Aug;19(8):651-8.Pubmed PMID: 4217619.

[12]. Sodek J. A new approach to assessing collagen turnover by using a microassay. A highly efficient and rapid turnover of collagen in rat periodontal tissues. Biochem J. 1976 Nov 15;160(2):243-6.Pubmed PMID: 1008854.

[13]. Sodek J. A comparison of collagen and non-collagenous protein metabolism in rat molar and incisor periodontal ligaments. Arch Oral Biol. 1978;23(11):977-82.Pubmed PMID: 285652.

[14]. Udenfriend S. Formation of hydroxyproline in collagen. Science. 1966 Jun 3;152(3727):1335-40.

[15]. Whitehead RG. Hydroxyproline creatinine ratio as an index of nutritional status and rate of growth. Lancet. 1965 Sep 18;2(7412):567-70.Pubmed PMID: 4158193.

[16]. Svanberg GK. Hydroxyproline determination in serum and gingival crevicular fluid. J Periodontal Res. 1987 Mar;22(2):133-8.Pubmed PMID: 2953884 .

[17]. Hara K, Takahashi T. Hydroxyproline content in gingival exudate before and after periodontal surgery. J Periodontal Res. 1975 Nov;10(5):270-4.Pubmed PMID: 129549.

[18]. Paunio K. On the hydroxyproline-Containing components in the gingival exudate. J. Periodontal Res. 1971 Apr;6(2):115-7.

[19]. Svanberg GK. Hydroxyproline titers in gingival crevicular fluid. J Periodontal Res. 1987 May;22(3):212-4.Pubmed PMID: 2955100.

[20]. Wynkoop JR, Woodyard S, Miller RA. A comparison of individual crevicular fluid hydroxyproline levels to periodontal assessments. J Dent Res. 1982;61(Special Issue):315.

[21]. Miller RA, Wynkoop JR, Johannsen K. Analysis of hydroxyproline in gingival exúdate by high performance liquid chromatography. Dent Res. 1982;61:275.

[22]. Silness J, Loe H. Periodontal Disease in Pregnancy. Ii. Correlation between Oral Hygiene and Periodontal Condtion. Acta Odontol Scand 1964;22:121135.

[23]. GREENE JC, VERMILLION JR. THE SIMPLIFIED ORAL HYGIENE INDEX. J Am Dent Assoc. 1964 Jan;68(1):7-13.Pubmed PMID: 14076341

[24]. Russell AL. The periodontal index.J. Periodontol.1967 Nov 1;38(6):Suppl-585.

[25]. Cimasoni G. Crevicular fluid updated. Monogr Oral Sci. 1983;12:24-8.

[26]. Pashley D. A mechanistic analysis of gingival fluid production. J. Periodontal Res. 1976 Apr;11(2):121-34.

[27]. Subrahmanyam MV, Sangeetha M. Gingival crevicular fluid a marker of the periodontal disease activity. Indian J Clin Biochem . 2003 Jan 1;18(1):5-7.

[28]. Koss MA, Castro CE, Salúm KM, Kishimoto E, Takagi S, López ME. Gingival crevicular fluid biomarkers in patients with gingivitis and chronic periodontitis. J. Hard Tissue Biol. 2010;19(2):111-6.

[29]. Johnston CS, Cartee GD, Haskell BE. Effect of ascorbic acid nutriture on protein-bound hydroxyproline in guinea pig plasma. J. Nutr. 1985 Aug 1;115(8):1089-93.

[30]. Akalin FA, Sengün D, Eratalay K, Renda N, Cağlayan G. Hydroxyproline and total protein levels in gingiva and gingival crevicular fluid in patients with juvenile, rapidly progressive, and adult periodontitis. J Periodontol. 1993 May;64(5):323-9.Pubmed PMID: 8515361

[31]. Koss MA, Castro C, Salúm KM, López ME. Changes in saliva protein composition in patients with periodontal disease. Acta Odontol Latinoam. 2009 Sep;22(2):105-12. 